\title{
Neutron-Dosimetric Support of Experiments Carried Out at RIAR Reactors
}

\author{
D.K. Ryazanov ${ }^{a}$, G.A. Shimansky, E.E. Lebedeva, and L.A. Volskaya
}

The paper presents methodical and technical developments combined to solve tasks related to neutron dosimetry at research reactors of different types.

\section{Introduction}

Radiation damage in materials is the key problem in providing safe operation of nuclear reactors. To solve it, changes in the materials are studied versus neutron spectrum and fluence based on irradiation performed in experimental channels of the research nuclear reactors.

The reliability of radiation effects determined in irradiated materials is provided both by measuring neutron spectrum and fluence used during irradiation and damageability calculations with an error of $5-10 \%$.

A separate task is the provision of constant neutron-dosimetric support of a large variety of irradiation experiments.

The paper describes the system for neutron-dosimetric support of irradiation experiments which is used at RIAR research reactors and complies with the up-to-date requirements to the accuracy in determining neutron - physical characteristics.

\section{RIAR Research Reactors}

The RIAR reactor complex includes the high-flux reactor SM operated on intermediate neutrons, pool-type reactors RBT-10, RBT-6 with the KORPUS facility, reactor MIR.M1 with autonomous loop facilities, and the fast neutron reactor BOR-60 with liquid sodium used as a moderator and coolant.

The high-flux reactor $\mathbf{S M}$ is intended for carrying out irradiation experiments of reactor material samples under the required conditions, studies of the mechanism of radiation induced changes in properties of various materials, production of radioactive nuclides, including far transuranium elements, and research in the field of nuclear physics.

The SM reactor is a vessel-type water-cooled reactor with a neutron trap that operates with intermediate neutrons. The reflector is made of beryllium oxide. Uranium enriched to $90 \%$ in uranium235 (dioxide dispersed in a metal matrix) is used as a fuel. The beryllium reflector has 30 channels $68 \mathrm{~mm}$ in diameter; the neutron trap has 27 channels $12 \mathrm{~mm}$ in diameter, and the core has 24 channels $12 \mathrm{~mm}$ in diameter $[1,2]$.

\footnotetext{
${ }^{a}$ Corresponding author: adm@niiar.ru
}

This is an Open Access article distributed under the terms of the Creative Commons Attribution License 2.0, which permits unrestricted use, distribution, and reproduction in any medium, provided the original work is properly cited. 
The RBT-6 and RBT-10 reactors are water-water pool-type reactors with the power 6 and $10 \mathrm{MW}$ accordingly. As a fuel they use spent fuel assemblies (FA) from the SM reactor. These reactors show a high stability of irradiation parameters over a long time period. They are intended for research in the field of reactor materials science $[1,2]$.

The KORPUS facility (the RBT-6 rector) is intended for simultaneous irradiation of a large number of structural material samples.

The fast neutron research reactor BOR-60 is intended for the testing of fuel cycle technologies, sodium coolant technology, as well as a wide range of design solutions for fast neutron reactors. Being a powerful source of fast neutrons, it is used for research of neutron irradiation's effect on structural, fuel and absorbing materials of various types $[1,2]$.

\subsection{Key Methodological Provisions}

The purpose of neutron irradiation metrology is to provide conformity of measurement results of neutron-physical characteristics of intensive neutron fields obtained in various nuclear reactors. A set of all used neutron fields should be integrated by one system for their certification, maintenance and control to provide consistency of the neutron measurements for reactor material science tasks.

According to metrological classification, neutron activation measurements are indirect and include some independent measuring procedures that can provide the highest reliability of results in identification of derivative values related to neutron physics [3]. Uncertainty measurement of a neutron value unit using modern standards is $\leq 2 \%$. To achieve the highest accuracy in neutron measurements in reactors a methodical regulation of the entire measuring process is needed. The methodical support should include a complex set of certified methods regulating all stages of neutron measurements in the specific reactor [4]. The complex of system elements includes the following methods:

- arrangement of irradiation and measurement of activity;

- identification of activation integrals;

- generation of neutron energy spectrum;

- generation of integral neutron-physical parameters;

- calculations of neutron characteristics, including damage dose and transmutation rates.

Neutron energy spectra in reactors are different. In this context, it is reasonable to arrange neutrondosimetric support in relation to a representative group of irradiation channels in a specific reactor. At the first stage, it is necessary to carry out calculation and experimental studies of neutron-physical characteristics in one of the channels from a chosen group. As a result, there is a possibility of its metrological certification as a reference neutron field or a secondary reference field with a status of a working standard.

Before installation of a particular device with irradiated materials into a chosen reactor channel, it is necessary to carry out a model experiment with simulation of the real load.

Monitoring of neutrons fluence during long-term irradiation is done by monitors located in specific places of the irradiation device (near samples for example). Spectrometry results in an empty channel, data of verification experiment, results of monitoring in a certain irradiation device and calculated data allow the recovery of neutron fluence values for tested samples. Thus, the task of proper transfer of neutron fluence measured by monitors to irradiated samples of tested materials is solved.

Arrangement of neutron-dosimetric support of irradiation experiments is shown in Fig. 1.

\subsection{Measuring Tools}

1. Sets of neutron activation detectors Certified sets of multi-purpose neutron activation detectors (NAD) [5] are used in the neutron activation experiments in the RIAR reactors.

Sets intended for the measurement of the characteristics of thermal neutron fields. 


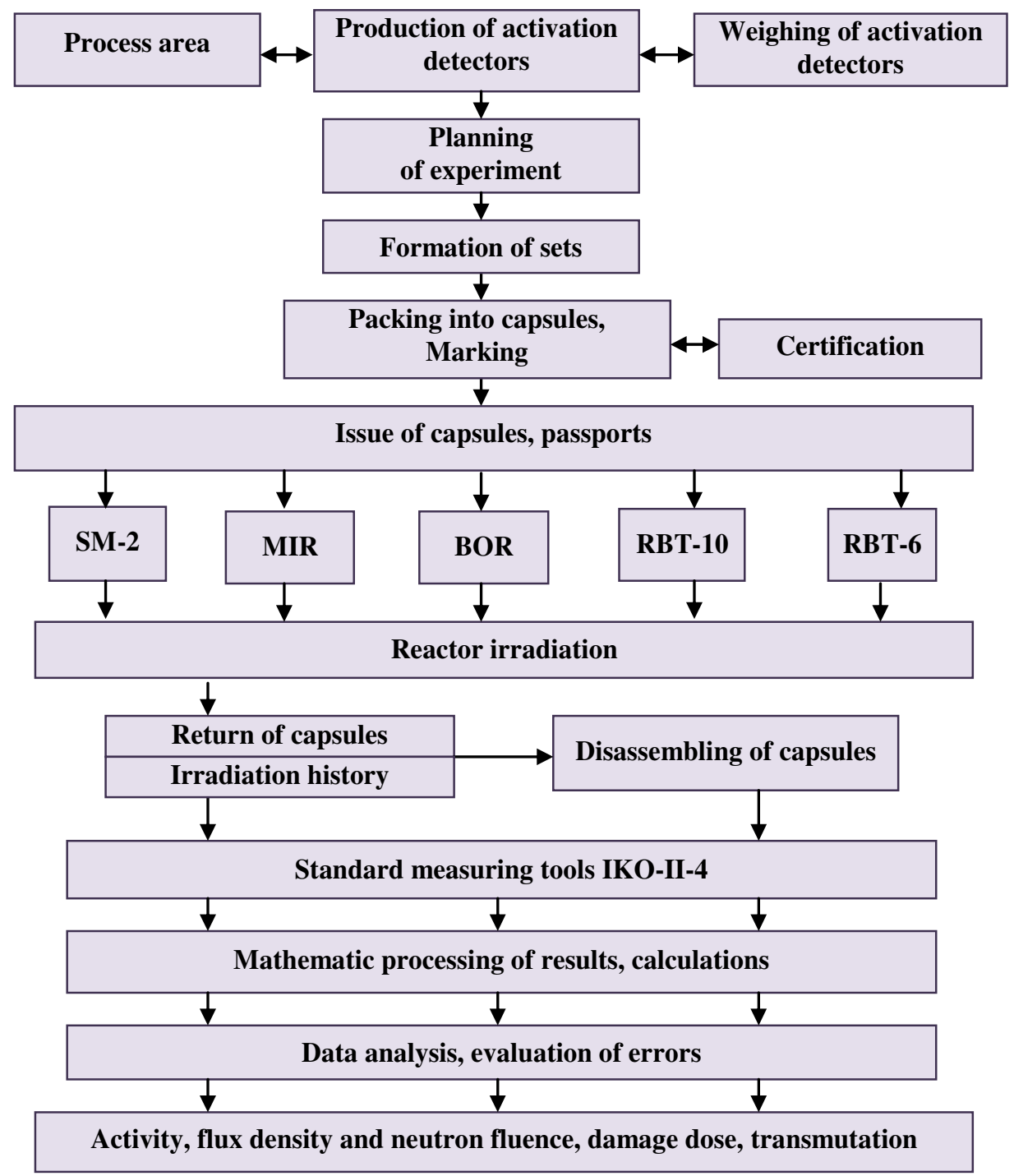

Figure 1. Materials science investigations dosimetric support flow chart.

This set includes detectors (all of them are aluminum alloy- based detectors) made from gold, cobalt, copper, manganese, lutetium, lanthanum, scandium, and indium. The number of nuclei is certified with an uncertainty of $2-3 \%$ for alloys (the confidence coefficient is $95 \%, \mathrm{k}=2$ ). There are special sets with a certification error of $2-3 \%$ for samarium, dysprosium, lutetium, cobalt, tantalum, and molybdenum.

During spectrometer measurements irradiation of these NADs is performed in aluminum and cadmium screens. The thickness of a cadmium wall is $1,0 \mathrm{~mm}$.

Sets intended for the measurement of the characteristics of fast neutron fields.

This set includes NADs made from natural metals: rhodium, indium, mercury, iron, niobium, nickel, zirconium, titanium. The number of nuclei is certified with an error of $1 \%$, for those with neptunium-3\%. There are special sets of detectors based on isotopes: ${ }^{204} \mathrm{~Pb},{ }^{60} \mathrm{Ni},{ }^{64} \mathrm{Zn},{ }^{54} \mathrm{Fe},{ }^{115} \mathrm{In},{ }^{111} \mathrm{Cd}$ with number of nuclei certified with an error of $2,5 \%$. 
A set of detectors that use metals (niobium, iron, titan, cuprum (isotope 63), nickel) is intended for support of long-term irradiation experiments. The certification error is $1 \%$. The dimensions and form of NADs are also standardized. The NADs are shaped as discs $1 \mathrm{~mm}$ in diameter and $0,15 \mathrm{~mm}$ thick. Thickness of the niobium disc is $0,08 \mathrm{~mm}$. The NAD sets are sealed into quartz tubes with a wall thickness of $1 \mathrm{~mm}$, and then packed into metal capsules made from aluminum, vanadium or stainless steel.

Niobium, iron, titanium alloyed with vanadium as well as iron and cobalt isotopes diluted in quartz are intended for high temperature conditions.

Because NADs are used as a reference measurement instrument, detectors are made of pure metals and each detector has the main characteristic i.e. the number of nuclei of an activated isotope with an error not more than $3 \%(\kappa=2)$.

\section{Equipment}

The activity of irradiated NADs was measured using an X-ray radiation spectrometer with a silicon semi-conductor detector, a gamma radiation spectrometer with a GEM-25 185-P germanium detector and a DSPEC PLUS analyzer, being a part of the certified measuring complex IKE-II-4. Due to the high activity of some NADs, measurements were carried out at several distances between the NAD and the certified detector. To obtain reaction rates and calculate errors, mathematical processing of measurement data was carried out using the certified software FUC, NAC, PARM-2 [6]. The statistical measurement error related to accumulation of pulses should not exceed $1 \%$.

\subsection{Reference Data}

The reference data may be split into four groups:

- energy dependence of activation reaction cross-sections;

- integral cross sections (effective, thermal, resonance integrals);

- characteristics of reaction products decay schemes;

- standard reactor neutron spectra.

Reaction cross sections. As differential cross sections $\sigma(\mathrm{E})$, a group representation in the international ENDF format (evaluated nuclear data file) is accepted. Different versions of the Russian RNMF and RNMF-D libraries are used. From foreign libraries the IRDF-90 file and the subsequent versions of this file [7,8] are used.

Integral cross sections. In fast neutrons dosimetry, values of effective threshold $\mathrm{E}_{\mathrm{ef}}$ for the NAD and corresponding effective cross section $\sigma_{\text {ef }}$ are of the highest practical value. Effective cross section for a specific reaction is calculated from differential cross section as an average of the reactor spectra. The effective cross section value is selected when calculated values $\sigma_{\text {ef }}$ are minimally spread provided that the neutron energy range in which the average cross section is calculated changes.

Characteristics of decay schemes. For neutron activation measurements, the key data from a decay scheme of radioactive reaction products include a half-life period (a decay constant), energy and absolute intensity of beta- and gamma-emissions [9].

Standard reactor neutron spectra (calculated and experimental). Availability of a library of standard reactor spectra is an obligatory element of metrological support for neutron measurements. Spectra are needed as a priori information for spectra recovery programs using experimental data, planning of experiments, assessment of cross sections, testing of techniques, etc. The Russian library file of reactor neutron spectra RSF-89 [10] includes not only calculation spectra, but also experimental ones, including well known standard neutron spectra "Benchmark". 


\subsection{Reference Neutron Fields in RIAR Reactors}

The reference neutron field may be applied as a reference gage at an enterprise operating several reactors or as a reference gage at a specific reactor. RIAR operating different types of research reactors uses:

- reference neutron field in the RBT-6 reactor - RF-4;

- secondary neutron reference fields (SRF):

- SRF-17 and SRF-18 - at the KORPUS facility in the RBT-6 reactor;

- SRF-13 - in the SM reactor;

- SRF-15 - in the BOR-60 reactor.

The reference neutron field in the reactor, being one of the key elements of the metrological support system of the neutron measurements in the reactor fields, is intended for the following metrological functions:

- reproduction of flux density and neutron fluence units;

- certification of other reactor fields by neutron spectrum;

- calibration of neutron spectrometry and radiometry instrumentation;

- certification of materials for the NAD production;

- carrying out of high-precision scientific and applied researches;

- use as a priori spectrum in recovery of the neutron spectra in other channels of a specific reactor.

To perform the listed functions, reference fields are used in combination with reference measuring tools. The reference field with a smaller set of metrological functions is certified as a secondary reference field. The certification technique for reference fields is the same for all reactors.

The main certified characteristic of a reference field is the differential neutron spectrum $\varphi_{0}(\mathrm{E})$. The spectrum is set within the energy range of $0,5 \mathrm{eV}-19 \mathrm{MeV}$ and represented in a normalized form. Another certified characteristic is the integral spectrum $\mathrm{F}_{0}(\mathrm{E})$.

In many cases, a reference neutron field allows the measurements of spectral characteristics to be brought to direct measurements by a method of activation relations.

Creation of a reference field starts with irradiation of several standardized NADs covering the entire range of neutrons energy by sensitivity in a selected channel of the reactor. Most irradiations were performed in cadmium and boron screens.

Table 1 presents the list of used reactions and experimental values of the reaction rates normalized for a reaction rate of ${ }^{58} \mathrm{Ni}(\mathrm{n}, \mathrm{p})$.

Table 1 also presents reaction rates calculated using the unfolded neutron spectrum. Errors of the unfolded spectrum were neglected. Deviations between the experimental and calculated values are shown in the last column of the table. Small deviations indicate a very good agreement of the used reaction cross sections in case of neutron spectrum recovery. Thus, this agreement characterizes the degree of reliability of the spectrum data. The reliability of the numerics can be estimated by errors in the data given in Tables 2, 3 .

The neutron spectrum was unfolded using the programs realizing a method of directed divergence within the energy range of $0,5 \mathrm{eV}-19 \mathrm{MeV}$. Figure 2 shows the differential neutrons spectrum from RF-4 (RBT-6 reactor) in coordinates $[\varphi(\mathrm{E}) \cdot \mathrm{E}, \lg (\mathrm{E})]$ compared to the prompt neutron spectrum of ${ }^{235} \mathrm{U}$ fission by thermal neutrons.

Based on the recovered spectrum and with the use of the recommended libraries of cross sections, integrated neutron-physical characteristics are calculated: effective cross sections of reactions, monitor coefficients, spectral coefficients, damage dose rate, reaction rates of the formation of helium and hydrogen. 
Table 1. Normalized experimental and calculated reaction rates.

\begin{tabular}{|l|l|l|c|c|c|}
\hline \multirow{2}{*}{ Reaction } & \multirow{2}{*}{ Cross section file } & \multicolumn{4}{|c|}{ Activation integrals } \\
\cline { 3 - 6 } & & Experiment & Uncert., $\%( \pm 2 \sigma)$ & Calculation & Deviation, $\%$ \\
\hline${ }^{237} \mathrm{~Np}(\mathrm{n}, \mathrm{f})$ & RNM & 13,85 & 7,0 & 13,86 & $-0,1$ \\
\hline${ }^{103} \mathrm{Rh}(\mathrm{n}, \mathrm{n})$ & RNM & 7,12 & 6,0 & 7,30 & $-2,6$ \\
\hline${ }^{47} \mathrm{Ti}(\mathrm{n}, \mathrm{x})$ & MXR & $1,65 \cdot 10^{-1}$ & 5,0 & $1,66 \cdot 10^{-1}$ & $-0,4$ \\
\hline${ }^{58} \mathrm{Ni}(\mathrm{n}, \mathrm{p})$ & RNM & 1,00 & 3,5 & 1,00 & 0 \\
\hline${ }^{54} \mathrm{Fe}(\mathrm{n}, \mathrm{p})$ & IRD & $7,34 \cdot 10^{-1}$ & 4,0 & $7,48 \cdot 10^{-1}$ & $-1,8$ \\
\hline${ }^{46} \mathrm{Ti}(\mathrm{n}, \mathrm{x})$ & MXR & $1,17 \cdot 10^{-1}$ & 5,0 & $1,21 \cdot 10^{-1}$ & $-3,2$ \\
\hline${ }^{63} \mathrm{Cu}(\mathrm{n}, \alpha)$ & IRD & $5,96 \cdot 10^{-3}$ & 5,0 & $5,98 \cdot 10^{-3}$ & $-0,3$ \\
\hline${ }^{48} \mathrm{Ti}(\mathrm{n}, \mathrm{p})$ & MXR & $3,50 \cdot 10^{-3}$ & 5,0 & $3,45 \cdot 10^{-3}$ & 1,5 \\
\hline${ }^{27} \mathrm{Al}(\mathrm{n}, \alpha)$ & IRD & $8,06 \cdot 10^{-3}$ & 4,0 & $8,29 \cdot 10^{-3}$ & $-2,9$ \\
\hline${ }^{93} \mathrm{Nb}(\mathrm{n}, 2 \mathrm{n})$ & RNM & $5,85 \cdot 10^{-3}$ & 4,0 & $5,93 \cdot 10^{-3}$ & $-1,4$ \\
\hline${ }^{45} \mathrm{Sc}(\mathrm{n}, \gamma)$ & IRD & 14,42 & 3,2 & 14,23 & 1,3 \\
\hline${ }^{164} \mathrm{Dy}(\mathrm{n}, \gamma)$ & MXR & $4,41 \cdot 10^{2}$ & 9,9 & $4,50 \cdot 10^{2}$ & $-2,1$ \\
\hline${ }^{176} \mathrm{Lu}(\mathrm{n}, \gamma)$ & MXR & $1,06 \cdot 10^{3}$ & 4,2 & $1,04 \cdot 10^{3}$ & 1,8 \\
\hline${ }^{115} \mathrm{In}(\mathrm{n}, \gamma)$ & RNM & $3,04 \cdot 10^{3}$ & 3,4 & $3,17 \cdot 10^{3}$ & $-4,2$ \\
\hline${ }^{181} \mathrm{Ta}(\mathrm{n}, \gamma)$ & B64 & $7,68 \cdot 10^{2}$ & 2,5 & $7,87 \cdot 10^{2}$ & $-2,5$ \\
\hline${ }^{197} \mathrm{Au}(\mathrm{n}, \gamma)$ & RNM & $1,61 \cdot 10^{3}$ & 2,0 & $1,71 \cdot 10^{3}$ & $-6,3$ \\
\hline${ }^{152} \mathrm{Sm}(\mathrm{n}, \gamma)$ & MXR & $3,05 \cdot 10^{3}$ & 7,6 & $3,15 \cdot 10^{3}$ & $-3,3$ \\
\hline${ }^{93} \mathrm{Nb}(\mathrm{n}, \gamma)$ & IRD & 9,10 & 2,6 & 9,39 & $-3,2$ \\
\hline${ }^{139} \mathrm{La}(\mathrm{n}, \gamma)$ & RNM & $1,232 \cdot 10$ & 3,0 & $1,23 \cdot 10$ & $-0,1$ \\
\hline${ }^{58} \mathrm{Fe}(\mathrm{n}, \gamma)$ & JEN & 1,40 & 3,6 & 1,40 & 0,3 \\
\hline${ }^{55} \mathrm{Mn}(\mathrm{n}, \gamma)$ & RNM & 14,55 & 3,0 & 14,50 & 0,3 \\
\hline${ }^{63} \mathrm{Cu}(\mathrm{n}, \gamma)$ & IRD & 4,79 & 4,5 & 5,07 & $-5,8$ \\
\hline${ }^{41} \mathrm{~K}(\mathrm{n}, \gamma)$ & MXR & 1,20 & 3,8 & 1,22 & $-1,2$ \\
\hline${ }^{23} \mathrm{Na}(\mathrm{n}, \gamma)$ & RNM & $3,51 \cdot 10^{-1}$ & 2,1 & $3,53 \cdot 10^{-1}$ & $-0,4$ \\
\hline
\end{tabular}

The activation integral of the ${ }^{58} \mathrm{Ni}(\mathrm{n}, \mathrm{p})^{58} \mathrm{Co}$ reaction is $2,70 \cdot 10^{-13} \mathrm{~s}^{-1}$ at $6 \mathrm{MW}$ reactor capacity.

Table 2. Spectral characteristics of neutron fields in the SM reactor.

\begin{tabular}{|c|c|c|}
\hline Parameter & Cell 44 (core) & Cell 52 (core) \\
\hline $\mathrm{F}_{\mathrm{GR}}$ & $2,24 \cdot 10^{14}( \pm 6,5)$ & $2,69 \cdot 10^{14}( \pm 7)$ \\
\hline $\mathrm{F}_{\mathrm{T}}$ & $1,00 \cdot 10^{14}( \pm 8)$ & $1,00 \cdot 10^{14}( \pm 9)$ \\
\hline $\mathrm{F}_{\mathrm{NT}}$ & $6,91 \cdot 10^{13}( \pm 4)$ & $9,09 \cdot 10^{13}( \pm 6)$ \\
\hline $\mathrm{F}(\geq .0,5 \mathrm{eV})$ & $2,73 \cdot 10^{15}( \pm 4)$ & $3,94 \cdot 10^{15}( \pm 7)$ \\
\hline $\mathrm{F}(\geq 0,1 \mathrm{MeV})$ & $1,54 \cdot 10^{15}( \pm 8)$ & $2,31 \cdot 10^{15}( \pm 10)$ \\
\hline $\mathrm{F}(\geq 0,5 \mathrm{MeV})$ & $1,08 \cdot 10^{15}( \pm 6)$ & $1,63 \cdot 10^{15}( \pm 7)$ \\
\hline $\mathrm{F}(\geq 1,0 \mathrm{MeV})$ & $7,62 \cdot 10^{14}( \pm 3)$ & $1,15 \cdot 10^{15}( \pm 5)$ \\
\hline $\mathrm{F}(\geq 3,0 \mathrm{MeV})$ & $1,85 \cdot 10^{14}( \pm 3)$ & $2,84 \cdot 10^{14}( \pm 3)$ \\
\hline $\mathrm{F}(0-20 \mathrm{MeV})$ & $2,95 \cdot 10^{15}( \pm 8)$ & $4,21 \cdot 10^{15}( \pm 8)$ \\
\hline \multicolumn{3}{|c|}{ Note. In brackets - measurement error in $\%, \mathrm{k}=2$} \\
\hline
\end{tabular}

Table 3. Neutron field characteristics.

\begin{tabular}{|c|c|c|c|}
\hline \multirow{2}{*}{ Parameter } & \multicolumn{3}{|c|}{ Thermal neutron flux density, $\mathrm{cm}^{-2} \mathrm{~s}^{-1}$} \\
\cline { 2 - 4 } & 3 & 10 & 23 \\
\hline $\mathrm{F}_{\mathrm{GR}}$ & $2,26 \cdot 10^{15} \pm 4 \%$ & $2,12 \cdot 10^{15} \pm 3 \%$ & $1,83 \cdot 10^{15} \pm 4 \%$ \\
\hline $\mathrm{F}_{\mathrm{T}}$ & $1,96 \cdot 10^{15} \pm 3 \%$ & $1,61 \cdot 10^{15} \pm 3 \%$ & $1,59 \cdot 10^{15} \pm 3 \%$ \\
\hline $\mathrm{F}_{\mathrm{NT}}$ & $1,31 \cdot 10^{14} \pm 3 \%$ & $1,00 \cdot 10^{14} \pm 3 \%$ & $1,23 \cdot 10^{14} \pm 3 \%$ \\
\hline$\beta$ & $-0,068$ & $-0,055$ & $-0,049$ \\
\hline$\beta-$ parameter of epithermal neutron spectrum (according to Westcott).
\end{tabular}




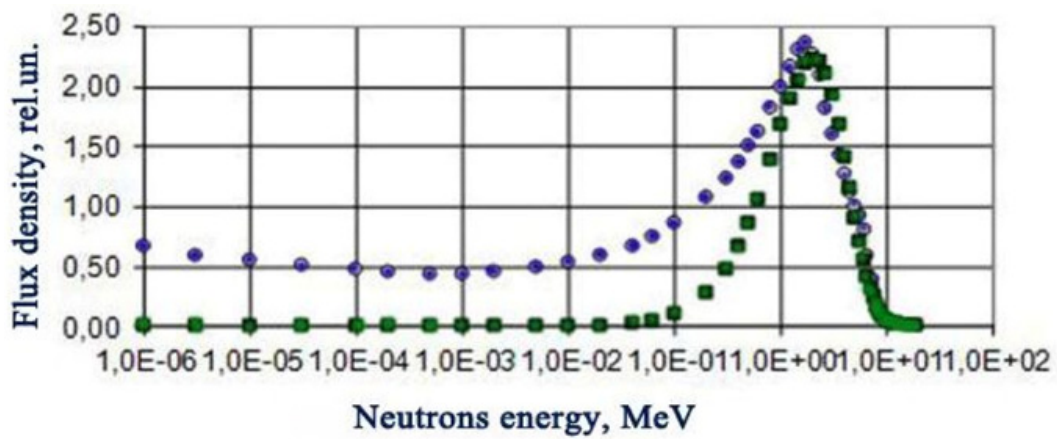

Figure 2. Differential spectra in a group representation: - spectrum of uranium fission by thermal neutrons; $o-$ spectrum from RF-4.

Verification of neutrons spectrum constancy at different reactor powers is also a part of a certification technique. Joint irradiations of specially selected pairs of detectors with sharply different sensitivity to neutrons of various energies were carried out for this purpose.

\subsection{Definition of Neutron Fluence}

Neutron fluence definition stands first among the tasks of neutron-dosimetric support. In almost all irradiation experiments, including reactor supervision, control of neutron fluence accumulated for a certain period, at least by fast neutrons, is necessary. There are certain features in the arrangement and identification technique of this value:

- duration of irradiation tests can range from hours to more than 10 years;

- the NAD dimensions should be small because irradiation places are hardly accessible and distortion of the spectrum caused by irradiated samples must be considered;

- environment temperature, taking into account radiation heating, can rise up to $1500{ }^{\circ} \mathrm{C}$;

- nature of irradiation tests is non-stationary, with possible stops and changes of power level and in some cases the neutron spectrum.

The above-listed conditions impose essential restrictions on a number of suitable activation reactions. A special set for activation monitoring of surveillance samples includes five types of NAD fluence for reactions $58 \mathrm{Ni}(\mathrm{n}, \mathrm{p}) 58 \mathrm{Co}, 54 \mathrm{Fe}(\mathrm{n}, \mathrm{p}) 54 \mathrm{Mn}, \mathrm{Ti}(\mathrm{n}, \mathrm{x}) 46 \mathrm{Sc}, 93 \mathrm{Nb}(\mathrm{n}, \mathrm{n}$ '), $93 \mathrm{mNb}, 63 \mathrm{Cu}(\mathrm{n}, \alpha) 60 \mathrm{Co}$. A set of monitors for long-term irradiations (more than 10 years) includes two NAD types: 93Nb, 54Fe. U238 and Np237 isotopes are not used because several reactions occur on them depending on neutrons energy. This causes additional difficulties in defining neutron fluence.

\section{Some Results}

\subsection{Reactor SM}

Because it is impossible to conduct researches in all the reactor channels, for a detailed study into spectral characteristics one typical channel was selected from each row.

Reactor core in the cross section is shaped as a square with two rows of fuel assemblies. A cylindrical neutron trap is located inside the core. There are 26 independent cells placed concentrically in the three rows in the trap. The moderator in the core and in the trap is water. 


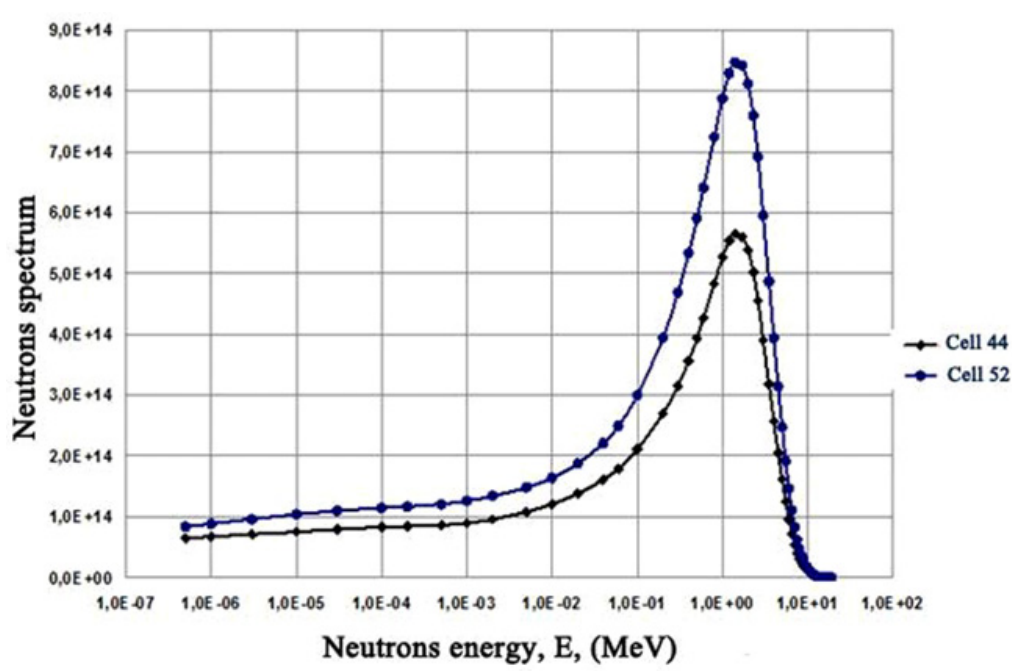

Figure 3. Differential neutron spectrum in cells 44 and 52 of the SM reactor core.

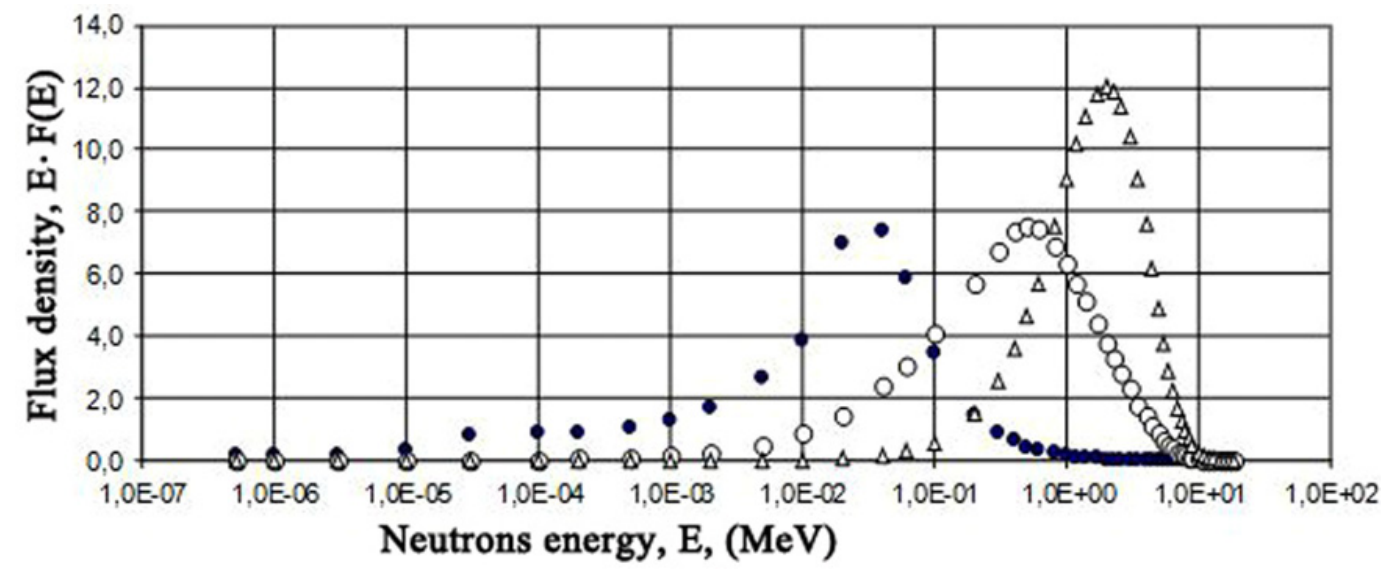

Figure 4. Differential neutron spectra: $\downarrow$ - VECh-4; o D23; $\Delta$-fission of ${ }^{235} \mathrm{U}(\mathrm{n}, \mathrm{f})$.

Unfolded differential neutron spectra in cells 44 (the first row), 52 (the second row) of the core fuel assemblies are shown in Fig. 3.

Integral characteristics - absolute values of neutron flux density integrated over different energy intervals are presented in Table 2.

Table 3 presents characteristics of the neutron flux for the three cells of the SM reactor neutron trap at $90 \mathrm{MW}$ reactor capacity.

\subsection{Reactor BOR-60}

Unfolded spectra (for the two cells of the BOR-60 reactor) compared to the U-235 fission spectrum are shown in Fig. 4. 


\section{$15^{\text {th }}$ ISRD}

Table 4. Neutron flux density, $\mathrm{cm}^{-2} \cdot \mathrm{s}^{-1}$, and average energy of spectra, $\mathrm{keV}$.

\begin{tabular}{|l|l|l|l|l|l|}
\hline \multirow{2}{*}{ Parameter } & \multicolumn{5}{|c|}{ Cells } \\
\cline { 2 - 6 } & D23 & B41 & E30 & B34 & D04 \\
\hline $\mathrm{F}(>0 \mathrm{MeV}), 10^{15}$ & $2,25( \pm 4,2)$ & $2,04( \pm 4)$ & $1,57( \pm 4,7)$ & $9,92( \pm 3,2)$ & $8,29( \pm 3)$ \\
\hline $\mathrm{F}(>0,1 \mathrm{MeV}), 10^{15}$ & $1,76( \pm 2,5)$ & $1,51( \pm 3)$ & $1,04( \pm 4)$ & $5,52( \pm 3)$ & $4,31( \pm 3)$ \\
\hline $\mathrm{F}(>0,2 \mathrm{MeV}), 10^{15}$ & $1,44( \pm 4,0)$ & $1,20( \pm 4)$ & $0,80( \pm 4)$ & $0,41( \pm 3)$ & $0,32( \pm 3)$ \\
\hline $\mathrm{F}(>0,5 \mathrm{MeV}), 10^{14}$ & $9,50( \pm 4)$ & $7,56( \pm 4,6)$ & $4,72( \pm 5)$ & $2,21( \pm 5)$ & $1,74( \pm 4)$ \\
\hline $\mathrm{F}(>1,0 \mathrm{MeV}), 10^{14}$ & $5,56( \pm 4)$ & $4,40( \pm 4)$ & $2,60( \pm 3)$ & $1,13( \pm 4)$ & $8,58( \pm 4)$ \\
\hline $\mathrm{F}(>3,0 \mathrm{MeV}), 10^{13}$ & $1,07( \pm 6)$ & $8,00( \pm 8)$ & $4,45( \pm 4,5)$ & $1,81( \pm 6)$ & $1,30( \pm 5)$ \\
\hline Eav, keV & 778 & 687 & 530 & 388 & 359 \\
\hline
\end{tabular}

There are practically no low energy neutrons in the BOR-60 reactor with sodium used as a moderator and coolant.

Table 4 summarizes the obtained flux densities and average energy of neutrons together with a relative $(\%)$ experimental uncertainty.

\section{Conclusion}

JSC "SSC RIAR" has developed a methodology and technical means for the neutron-dosimetric analysis of reactor experiments in a wide range of irradiation conditions (neutron fluence achieving $5 \cdot 10^{23} \mathrm{~cm}^{-2}$, flux density achieving $5 \cdot 10^{15} \mathrm{~cm}^{-2} \mathrm{~s}^{-1}$, damage dose up to $100 \mathrm{dpa}$ ) with an accuracy meeting up-todate domestic and foreign requirements.

A concept has been developed and implemented to provide a uniformity of measurements performed at different types of reactors. The concept is based on a combination of approaches comprising certification of reference means for neutron-activation measurements: measurement techniques, provision with constants, software, sets of neutron-activation detectors, materials to fabricate neutronactivation detectors, cadmium and boron neutron filters.

Techniques and software have been developed to get a full set of neutronic characteristics of the reactor core and channels: activation integrals, neutron energy spectra, fast and thermal neutron flux density, fast and thermal neutron fluence and damage dose.

\section{References}

[1] RIAR's Research Reactors and their Experimental Capabilities. V.A. Tsykanov, Prof., Dimitrovgrad, RIAR, 1991

[2] A.L. petelin, V.V. Kalygin, E.A. Zvir, A.L. Izhutov, S.A. Il'enko, S.G. Eremin, V.A. Starkov. "Modern Methods to Study Material and Fuel in research Reactors". JSC"SSCRIAR", Conf. "New Materials for Innovative Development of Nuclear Power Engineering", Dimitrovgrad, 2014

[3] Yu. I. Gregadze, E.K. Stepanov, V.P. Yaryna. Applied Methodology of Ionizing Emission. M. Energoatomizdat, 1990

[4] D.K. Ryazanov. Spectrometry and Dosimetry of Neutrons at research Reactors. Monography. Dimitrovgrad. MEPhI, 2013. P. 294

[5] E.I. Grigoriev. Neutron-Activation Detectors. State and Future. Measurement Engineering, 1996, \#1, P. 48

[6] G.A. Simansky. Automatic System for Spectrometry Measurements Processing FUC-NAC // Proc. Dimitrovgrad: JSC RIAR, 1996. \#.4. - P. 37-43

[7] E.I. Grigoriev, V.P. Yaryna, A.A. Lapenas, K.I. Zolotarev, N.V. Kornilov, A.B. Pashchenko, V.S. Troshin, H.Ya. Bondras. Neutron-Activation detectors for Reactor Measurements. Crosssections of Neutron-to-Nuclei Interaction. GSSSD 131-89. M.: Standards Publishers, 1990 
[8] Kocherov N.P. and McLaughlin P.K. The International Reactor Dosimetry File. (IRDF-90, version 2). IAEA, NDS-141, Rev.2, Oct. VIENNA, 1993

[9] T.V. Golashvili, V.P. Chechev, Reference of Nuclides. M. : IPPE Publishing House, 2011

[10] G.V. Tarnovsky, V.S. Troshin, L.V. Chubarova, V.P. Yaryna, File of Reactor Neutron Spectra RSF-89 // proc. Of the $5^{\text {th }}$ All-Russia Meeting on Metrology of Neutron Emission at Reactors and Accelerators. NPO VNIIFTRI Publishers. 1990, P. 151-153 